\section{Improved Cucumber Transformation by a Modified Explant Dissection and Selection Protocol}

\author{
Prem Anand Rajagopalan and Rafael Perl-Treves ${ }^{1}$ \\ Faculty of Life Sciences, Bar Ilan University, Israel
}

\section{Additional index words. Cucumis sativus, cucumber, Agrobacterium transformation, direct regeneration}

\begin{abstract}
Agrobacterium-mediated transformation of Cucumis sativus L. cotyledons was investigated, to identify important factors that affect transformation efficiency. The factors evaluated were initial explant preparation, including preculture, pricking of the explant, inoculation time and co-cultivation regime. We also modified the selection regime, compared to previously published protocols. Our results show that dissecting the proximal half of the cotyledon by a $\mathrm{V}$-shaped cut resulted in a higher transformation rate, compared to two other methods of dissection, as indicated by transient $\beta$-glucuronidase gene expression. Selection on $100 \mathrm{mg} \cdot \mathrm{L}^{-1} \mathrm{kanamycin}$ resulted in the early development of nontransformed shoots, whereas a gradual increase of kanamycin concentration up to $200 \mathrm{mg} \cdot \mathrm{L}^{-1}$ resulted in the subsequent formation of transgenic shoots on the same medium. The overall transformation frequency in these experiments, expressed as the number of rooted, confirmed transgenic plants per initial number of explants, was $1.7 \%$. The stable integration of T-DNA was confirmed in the primary transformants and their progeny. Abbreviations: $\mathrm{ABA}=$ abscisic acid; $\mathrm{AdS}=$ adenine sulfate; $\mathrm{AS}=$ acetosyringone; BA = 6-benzylaminopurine; $\mathbf{G A}_{3}=$ gibberellic acid; IBA = indolebutyric acid.
\end{abstract}

Cucumber (Cucumis sativus L.) is one of the world's most important vegetable crops (Esquinas-Alcazar and Gulick, 1983). Conventional breeding of cucumber to improve disease resistance and other horticultural traits is limited by its narrow genetic basis and severe incompatibility barriers to related species (Kho et al., 1980) and it would be therefore desirable to apply genetic engineering tools to improve the crop.

Agrobacterium tumefaciens-mediated gene transfer is still far from routine in many recalcitrant plant species, including Cucumis sativus. In a few reports, transgenic plants have been obtained via somatic embryogenesis, starting from Agrobacterium-infected petiole explants of $C$. sativus 'Endeavor' (Raharjo et al., 1996; Raharjo and Punja, 1996). Others used hypocotyl explants of line 1021 (Nishibayashi et al., 1996) or 'Poinsett 76' (Chee, 1990a, 1990b). Two genotypes of pickling cucumbers were transformed by applying A. tumefaciens to petiole and leaf segments (Sarmento et al., 1992). Other studies induced the direct regeneration of transformed shoots, rather than somatic embryos, from cotyledon explants of cultivars Poinsett 76 and Green Long (Tabei et al., 1994; Vengadesan et al., 2003 and preliminary report in Ganapathi and Perl-Treves, 2000). However, direct regenera-

Received for publication 24 May 2004. Accepted for publication 19 Aug. 2004. The authors thank Victor Gaba and Gopalasamy Vengadesan for critical reading of the manuscript. This research was funded by Grant US 3139-99 from the United States-Israel Binational Agricultural Research and Development Fund and by Grant I-682-166, 12/2000 of the German Israel Foundation for Scientific Research and Development.

${ }^{1}$ Corresponding author; e-mail perl@mail.biu. ac.il. tion of transgenic cucumber from cotyledon explants is a low-efficiency protocol, with high proportions of nontransformed 'escapees' following selection. We estimate that this is due, at least in part, to poor knowledge regarding the preparation and handling of the cotyledon explants. Moreover, in most of the above-mentioned studies, the effect of various experimental variables was not reported, and the frequency of transformed plants recovered

Fig. 1.Explant preparation, shoot induction and GUS expression following Agrobacterium-mediated transformation of explants. (A) Dissection of cotyledon explants from 2-d-old, partially germinated seed. Type I explant: cotyledons were detached from the embryo axis and the entire cotyledon was used. Type II = the proximal 5 -mm portion of the cotyledon was excised by performing a straight cut. Type III = a V-shaped cut was made at the proximal end, to remove only a minimal amount of preexisting meristematic region. (B) Type III cotyledon explants taken for GUS analysis $7 \mathrm{~d}$ after co-cultivation (area assayed for GUS activity is indicated). (C) GUS foci in the proximal region of a Type III explant, indicating transient espression of the transgene (bar $=1.6 \mathrm{~mm}$ ). (D) Adventitious buds begin to form in the proximal regions of the cotyledon explants (the boxed region was taken for GUS pression in differentiating, 3-week-old cotyledon explants $(\mathrm{bar}=2.3 \mathrm{~mm})$. $(\mathbf{F})$ Regeneration of transgenic shoots in Shoot Induction Medium with $100 \mathrm{mg} \cdot \mathrm{L}^{-1} \mathrm{kan}$ after 4 weeks of culture. (G-F) Selection of regenerated shoots in increasing concentration of kanamycin. (G) Early, nontransformed green shoots (ES) that form on the Shoot Induction medium. (H) Isolated single leaf differentiating from cut ends of the cotyledon explants. (I) The early shoots (ES) are surrounded by newly developing shoots (NS). (J) Putative transgenic shoots in elongation medium in the presence of $200 \mathrm{mg} \cdot \mathrm{L}^{-1} \mathrm{kan}$. assay in Fig. 1E; bar $=2.6 \mathrm{~mm}$ ). (E) GUS ex- was not indicated. For these reasons we decided to reexplore A. tumefaciens transformation of cucumber using cotyledons as the explant source. In this study we quantitatively evaluate factors that affect transformation, such as explant preparation, i.e., the source, size and age of the explant, and the wounding practice. The selection protocol applied during direct regeneration of the plants was modified, to minimize the probability of regeneration of nontransformed plants. The influence of different conditions on the efficiency of gene transfer was assessed using constructs that express the GUS-intron system. The optimized transformation procedure described in this paperimproves the reproducibility and the recovery rates of stably transformed plants.

\section{Materials and Methods}

Agrobacterium tumefaciens suspension culture. Genetic transformation was performed using Agrobacterium strain EHA105. We used plasmid construct pME504 (Edelman et al., 2000), derived from pGA492 (An et al., 1986), that includes the nptII (neomycin phosphotransferase) and bar (phosphinotricine
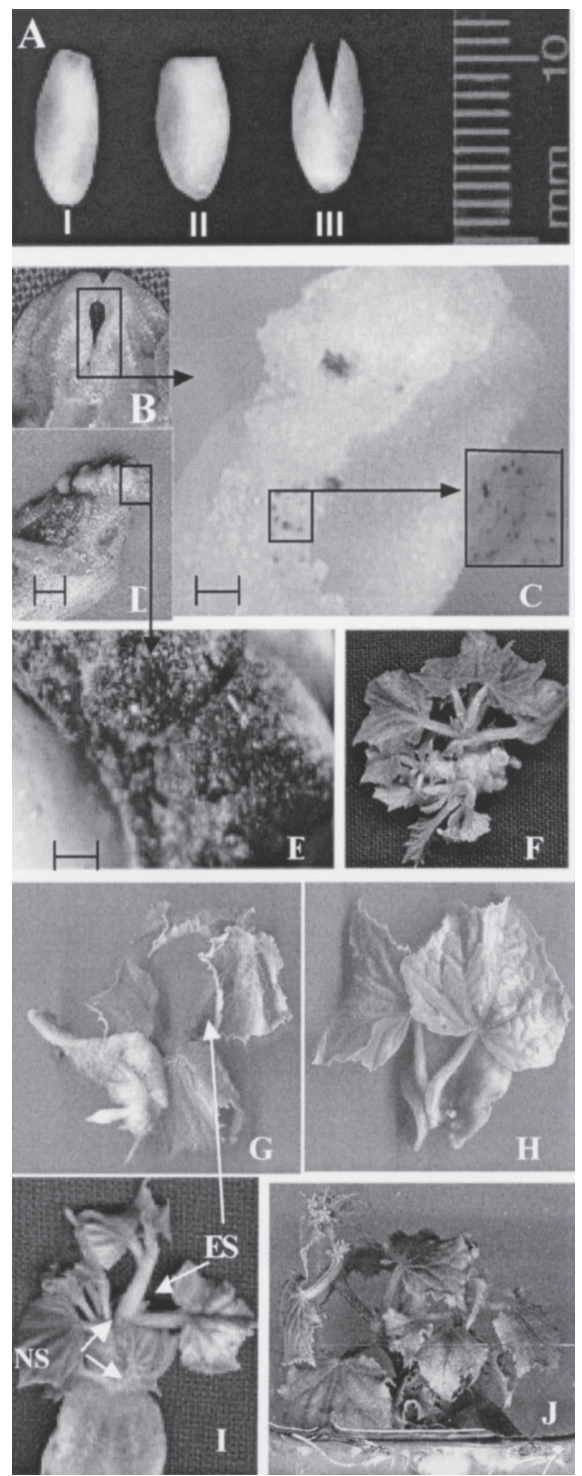
resistance) selection markers, driven by the CaMV-35S promoter. pME504 also harbors a modified uidA gene, coding for $\beta$-glucuronidase (GUS) with an intron within the open reading frame, to prevent its expression in Agrobacterium. Bacterial cultures were started from a single colony of Agrobacterium tumefaciens, cultured in $3 \mathrm{~mL}$ of AB minimal medium (pH 7.2) (Chilton et al., 1974) with $50 \mu \mathrm{g} \cdot \mathrm{mL}^{-1}$ of kanamycin at $28^{\circ} \mathrm{C}$ on a rotary shaker $(200$ rpm). After overnight culture, $200 \mu \mathrm{L}$ were transferred to $50 \mathrm{~mL}$ of $\mathrm{AB}$ minimal medium (pH 7.2) and incubated for 5 to $6 \mathrm{~h}$ at $200 \mathrm{rpm}$ on a rotary shaker. The culture was centrifuged at $3000 \mathrm{rpm}$ for $10 \mathrm{~min}$ at $27^{\circ} \mathrm{C}$ and the pellet adjusted to 1.0 O.D. ${ }_{600}$ in $\mathrm{AB}$ minimal medium (pH 5.2), supplemented with $20 \mu \mathrm{M}$ acetosyringone.

Explant and media preparation. Seeds of Poinsett 76 were obtained from Peto Seeds. The seed coats were peeled, and the seeds were surface sterilized by soaking in $50 \%(\mathrm{v} / \mathrm{v})$ commercial bleach (consisting of 3\% sodium hypochlorite) for $10 \mathrm{~min}$ with gentle shaking $(100 \mathrm{rpm})$. The seeds were then rinsed three times with sterile distilled water and soaked for $30 \mathrm{~min}$ in water. The seeds were air-dried for $5 \mathrm{~min}$ in a laminar flow hood and germinated in the dark for $2 \mathrm{~d}$ in $10 \times 150 \mathrm{~mm}$ Petri dishes containing hormone-free MS medium (Murashige and Skoog, 1962). All the media used for germination, preculture, co-cultivation, shoot-induction, elongation and rooting were adjusted to $\mathrm{pH} 5.7$ before autoclaving, supplemented with $87.64 \mathrm{~mm}$ sucrose and solidified with $0.15 \%$ Gelrite, unless otherwise specified. Cultures were grown in a controlled environment at $25 \pm 2{ }^{\circ} \mathrm{C}$ under cool white fluorescent light with a 16 -h photoperiod.

Three types of cotyledonary explants were prepared from partially germinated seeds, by varying the way by which the explant was cut to remove the embryo and adjacent tissue (Fig. 1A). For Type I explants, the two cotyledons were detached from the embryo axis and the entire cotyledon was used. For Type II explants, the proximal 5-mm portion of the cotyledon was excised, by performing a straight cut perpendicular to the cotyledon midrib. For Type III explants, a V-shaped cut (about $0.5 \mathrm{~cm}$ long) was made at the proximal end, close to the midrib. The explants were placed on MS induction medium containing 6-benzylaminopurine (BA; $4.4 \mu \mathrm{M})$, abscisic $\operatorname{acid}(\mathrm{ABA} ; 3.8 \mu \mathrm{M})$ and adenine sulfate (AdS; $108.5 \mu \mathrm{M})$ for $72 \mathrm{~h}$ preculture.

Co-cultivation and selection. Precultured cotyledons were collected in a sterile Petri plate and the proximal region of the explant was pricked 4 to 5 times with a sterile needle that had been dipped in $200 \mu \mathrm{M}$ acetosyringone (AS). About $10 \mathrm{~mL}$ of bacterial suspension were added to each plate and the plates were swirled gently for $10 \mathrm{~min}$ at $24^{\circ} \mathrm{C}$. The infected cotyledons were blotted dry using sterile filter paper and co-cultivated for $48 \mathrm{~h}$ under light with a 16-h photoperiod, on Induction Medium without AS. After co-cultivation, cotyledons were washed with liquid halfstrength MS basal medium containing 300 $\mathrm{mg} \cdot \mathrm{L}^{-1}$ cefotaxime, until the wash solution was completely clear. The cotyledons were blotted dry and placed, abaxial side up, on MS Induction Medium supplemented with $100 \mathrm{mg} \cdot \mathrm{L}^{-1} \mathrm{kanamycin}(\mathrm{kan})$ and $300 \mathrm{mg} \cdot \mathrm{L}^{-1}$ cefotaxime. After 2 weeks, explants that had already formed shoot-buds were transferred to MS elongation medium, containing BA $(0.44$ $\mu \mathrm{M})$, gibberellic acid $\left(1.4 \mu \mathrm{MGA}_{3}\right), 150 \mathrm{mg} \cdot \mathrm{L}^{-1}$ kan and $300 \mathrm{mg} \cdot \mathrm{L}^{-1}$ cefotaxime. The remaining explants were subcultured on the same induction medium for another 2 weeks, and then the responding explants were transferred to elongation medium supplemented with 150 $\mathrm{mg} \cdot \mathrm{L}^{-1} \mathrm{kan}$ and $300 \mathrm{mg} \cdot \mathrm{L}^{-1}$ cefotaxime. In many cases, shoots were moved to $200 \mathrm{mg} \cdot \mathrm{L}^{-1} \mathrm{kan}$ for further confirmation of their resistance. The survival rate of explants and frequency of shoot regeneration were recorded four weeks after co-cultivation.

After 3 weeks on elongation medium, the shoots were individually separated from the senescing cotyledons and transferred either to elongation medium or rooting medium, depending on their size. The 6 to $7 \mathrm{~cm}$ long shoots were placed on rooting medium, consisting of half-strength $\mathrm{MS}, 0.5 \mathrm{mg} \cdot \mathrm{L}^{-1} \mathrm{IBA}$ and $100 \mathrm{mg} \cdot \mathrm{L}^{-1} \mathrm{kan}$. The smaller shoots were subcultured for 2 additional weeks in elongation medium before rooting. The percentage of rooted shoots was recorded 9 weeks after co-cultivation. After three weeks on rooting medium, plants that had 2 to 3 well-developed roots were transferred to Jiffy pots in the growth chamber $\left(27 \pm 2{ }^{\circ} \mathrm{C}, 16\right.$-h photoperiod $)$ and then to greenhouse conditions.

GUS assay. The GUS assay (Jefferson et al., 1987) was carried out during the regeneration period. Transient expression was determined three days after co-culture by examining the number of GUS positive foci present on the explant. Stable expression of the reporter gene was recorded after 4 weeks of kanamycin selection, by counting the number of GUS positive buds.

Southern hybridization and PCR analysis. PCR analysis was used to confirm the presence of the transgene in primary transformants and their progeny. PCR reactions were carried out in a $50 \mu \mathrm{L}$ volume containing template DNA (100 ng), $200 \mu \mathrm{M}$ of each dNTP (Roche, Germany), $1 \mu \mathrm{M}$ of each primer(Genosys-Sigma), $1 \mathrm{U}$ Taq DNA polymerase, $1.5 \mathrm{~mm} \mathrm{MgCl}_{2}$ and $1 \times$ Taq DNA polymerase buffer. The primer sequences were $n p t$ II Forward - 5'GCC GCT TGG GTG GAG AGG CTA T-3' and $n p t ~ I I$ Reverse - 5'GAG GAA GCG GTC AGC CCA TTC G-3', yielding an amplification product of about $600 \mathrm{bp}$. Annealing temperature was 55 ${ }^{\circ} \mathrm{C}$. At least two PCR replicates were carried out for each plant. Putative transgenic plants were also tested by Southern blot hybridization according to Sambrook et al. (1989). Genomic DNA was isolated from putative transformants, their progeny and control untransformed plants according to Dellaporta et al. (1993). Five micrograms of DNA from each plant were digested overnight with HindIII or PstI, resolved in $0.8 \%$ agarose gels and blotted onto 'Gene Screen' membranes (NEN, USA). A600 bp fragment of the nptII gene was used as a probe. After hybridization at $65^{\circ} \mathrm{C}, 5 \times \mathrm{SSC}$ with the random-primed, ${ }^{32} \mathrm{P}-\mathrm{dATP}-\mathrm{labeled}$ fragment, the membrane was washed twice at $65^{\circ} \mathrm{C}$ in $0.5 \times \mathrm{SSC}, 0.1 \times \mathrm{SDS}$ and exposed to a phosphor-imager (BAS 1500, Fuji, Japan).

Statistical analysis. The experiment that analyzed factors that affect transient transformation frequency was run in three replicates, with about 100 explants per replicate per treatment. A sample of about 15 explants per replication was assayed for the appearance of GUS-expressing foci. To compare explant types, we analyzed three replications, each consisting of 100 cotyledons. Regeneration and transformation scores were analyzed by single-factor analysis of variance (ANOVA). The mean variance data were subjected to Duncan multiple range test (DMRT) (Gomez and Gomez, 1976) and to the Tukey and Kramer HSD test (SAS Institute, 1996).

\section{Results and Discussion}

Factors affecting transient transformation and shoot regeneration. In this study, regeneration of Cucumis sativus plants from cotyledonary explants was based on Malepszy and Nadolska-Orezyk, (1983) and Kim et al. (1988), while the transformation method was based on Tabei et al. (1994). In the first series of experiments, we report the optimization of factors affecting Agrobacterium-mediated gene delivery. Rates of transient GUS expression, as well as regeneration of shoot buds in the presence of kanamycin were monitored, to assay the effect of different variables. The other variables were kept constant according to the protocol given in the Materials and Methods.

The optimal duration of cotyledon preculture was studied by subjecting explants to preculture periods that ranged between 0 and $96 \mathrm{~h}$ before Agrobacterium inoculation. One week after co-cultivation, a sample of 15 explants was assayed for the appearance of GUS-expressing foci, that report transient transformation events. The remaining explants (about 85/replication) were cultured in Shoot Induction Medium and the number of shoots developing on $100 \mathrm{mg} \cdot \mathrm{L}^{-1} \mathrm{kan}$ was scored after 4 weeks.

Explant survival, transient GUS expression and rate of regeneration of kanamycin- resistant shoots were significantly affected by the duration of the preculture treatment (Table 1). Cotyledons that were not precultured at all had the lowest survival rate, and the lowest rates of transient GUS expression. Conversely, the highest number of GUS positive foci and shoots were obtained after $72 \mathrm{~h}$ preculture. When preculture time was increased to $96 \mathrm{~h}$, survival and regeneration rates did not change much, but the frequency of transient expression events was reduced.

After preculture, the cotyledons were pricked with a needle and immersed in an Agrobacterium suspension. We either applied light wounding, i.e., each explant was pricked 5 times, or heavy wounding-10 times. As shown in Table 1B, pricked explants underwent transient transformation more often, but had lower rates of regeneration. Explant survival did not differ significantly between the control 
and lightly pricked explants. This treatment should probably be recommended due to the higher rates of initial transformation, despite the decrease in regeneration rate. The heavier wounding treatment, on the other hand, was clearly detrimental.

Precultured explants were immersed in the bacterial culture for periods ranging from $1 \mathrm{~min}$ to $3 \mathrm{~h}$. Following immersion, the explant was blotted and placed on antibiotic-free cocultivation medium. As shown in Table 1, the frequency of transient GUS expression events increased with inoculation time, but survival rate and regeneration capacity were dramatically reduced. We therefore selected 10 minutes of inoculation as our recommended protocol.

A similar trend was observed with varying co-culture periods: shorter periods $(24 \mathrm{~h})$ correlated with higher survival rates (Table 1). Of the surviving explants, those that had been co-cultured for 24 to $48 \mathrm{~h}$ had the highest rates of adventitious bud formation. Extended co-culture periods ( 96 to $120 \mathrm{~h}$ ) significantly reduced survival and regeneration rates of explants. We concluded that 48 to $72 \mathrm{~h}$ of coculture represented a reasonable compromise between survival, regeneration and transient expression rates.

To test the effect of light conditions during co-cultivation, we co-cultivated cotyledons and bacteria for $48 \mathrm{~h}$ either in complete darkness, or under a 16/8 $\mathrm{h}$ light/dark photoperiod $\left(20 \mu \mathrm{mol} \cdot \mathrm{m}^{-2} \cdot \mathrm{s}^{-1}\right)$. There was no difference in transient GUS expression between the dark and light treatments. However, light-grown cotyledons had a higher survival rate and significantly higher regeneration (Fig. 2). In Cucumis sati$v u s$, published protocols specifically used dark co-cultivation (Chee 1990b, Tabei et al., 1998), probably because Agrobacterium grows faster in the dark. Our results indicate that co-cultivation should be carried out in the light, but the physiological basis for this remains to be identified.

The beneficial effect of preculture treatments on explant survival and on transient expression observed in our study agrees with Sarmento et al. (1992), who found efficient T-DNA delivery following two day-long preculture of cucumber hypocotyls. The effect of explant wounding before inoculation was not reported previously in cucumber. However, Choi et al. (1994) demonstrated that preculturing watermelon (Citrullus lanatus) cotyledon explants followed by pricking increased the percentage of transformed plants. In many systems, adding acetosyringone (AS) to the Agrobacterium culture and/or co-cultivation medium proved to be beneficial (Boase et al., 1998; Wu et al., 2003). Nishibayashi et al. (1996) and Mohiuddin et al. (2000) supplemented their bacterial cultures with $20 \mu \mathrm{M} \mathrm{AS}$ and reported improved cucumber transformation rates. Our protocol includes AS in the bacterial suspension medium; we also added AS at different concentrations ( 0 to 200 $\mu \mathrm{M})$ to the preculture and co-cultivation plates, but observed no improvement in transient transformation (data not shown).

Dissection of cotyledonary explants. In the next set of experiments, we compared three different ways of dissecting the cotyledon explants prior to transformation, as detailed in the Materials and Methods (Fig. 1A). The three explant types were infected using our standard conditions and regeneration was induced on the Shoot Induction Medium. One week after co-cultivation, about $90 \%$ of the explants had enlarged 5 to 6 times. At this stage we determined the rate of transient expression, as reflected by the appearance of GUS-expressing foci in a sample of 15 cotyledons /replicate

Table 1. Effect of preculture, inoculation time and length of co-cultivation on explant survival, percentage of transient GUS expression and frequency of regeneration in Type III cotyledon explants.

\begin{tabular}{|c|c|c|c|c|}
\hline Variable & $\begin{array}{l}\text { Variable } \\
\text { treatment }\end{array}$ & $\begin{array}{l}\text { Survival } \\
\operatorname{rate}^{z}(\%)\end{array}$ & $\begin{array}{l}\text { Cotyledons with } \\
\text { GUS foci }(\%)\end{array}$ & $\begin{array}{l}\text { Frequency of } \\
\text { regeneration }(\%)\end{array}$ \\
\hline \multirow[t]{5}{*}{ Preculture $^{w}(h)$} & 0 & $56 \mathrm{~d}^{\mathrm{v}}$ & $40 \mathrm{e}$ & $47 \mathrm{c}$ \\
\hline & 24 & $63 \mathrm{c}$ & $60 \mathrm{~d}$ & $62 \mathrm{~b}$ \\
\hline & 48 & $71 \mathrm{~b}$ & $63 \mathrm{c}$ & $61 \mathrm{~b}$ \\
\hline & 72 & $73 \mathrm{a}$ & $92 \mathrm{a}$ & $65 \mathrm{a}$ \\
\hline & 96 & $71 \mathrm{~b}$ & $75 \mathrm{~b}$ & $65 \mathrm{a}$ \\
\hline \multirow{3}{*}{ Pricking of the explants } & None & $75 \mathrm{a}$ & $55 \mathrm{c}$ & $71 \mathrm{a}$ \\
\hline & 5 times & $76 \mathrm{a}$ & $85 \mathrm{~b}$ & $61 \mathrm{~b}$ \\
\hline & 10 times & $63 \mathrm{c}$ & $87 \mathrm{a}$ & $55 \mathrm{c}$ \\
\hline \multirow[t]{7}{*}{ Inoculation time (min) } & 1 & $88 \mathrm{a}$ & $43 \mathrm{f}$ & $70 \mathrm{a}$ \\
\hline & 10 & $76 \mathrm{~b}$ & $61 \mathrm{e}$ & $64 \mathrm{c}$ \\
\hline & 15 & $75 \mathrm{~b}$ & $83 \mathrm{~d}$ & $60 \mathrm{~d}$ \\
\hline & 30 & $64 \mathrm{c}$ & $85 \mathrm{c}$ & $68 \mathrm{~b}$ \\
\hline & 60 & $51 \mathrm{~d}$ & $93 \mathrm{~b}$ & $33 \mathrm{e}$ \\
\hline & 120 & $33 \mathrm{e}$ & $93 \mathrm{~b}$ & $27 \mathrm{f}$ \\
\hline & 180 & $16 \mathrm{f}$ & 96 a & $11 \mathrm{~g}$ \\
\hline \multirow[t]{5}{*}{ Co-cultivation time (h) } & 24 & $72 \mathrm{a}$ & $42 \mathrm{e}$ & $65 \mathrm{a}$ \\
\hline & 48 & $69 c$ & $60 \mathrm{~d}$ & $66 \mathrm{a}$ \\
\hline & 72 & $71 \mathrm{ab}$ & $86 \mathrm{bc}$ & $59 \mathrm{~b}$ \\
\hline & 96 & $44 \mathrm{~d}$ & $87 \mathrm{ab}$ & $39 \mathrm{c}$ \\
\hline & 120 & $41 \mathrm{e}$ & 88 a & $28 \mathrm{~d}$ \\
\hline
\end{tabular}

${ }^{2}$ Percentage of healthy green cotyledons, recorded 4 weeks after co-culture. The experiment was run with three replicates, with about 100 explants per replication for each treatment.

${ }^{y}$ Randomly selected 15 cotyledons were assayed for GUS expression. The percentage of the surviving explants with numerous foci of GUS expression is given.

${ }^{x}$ Regeneration frequency was calculated as the proportion of cotyledons producing shoots on $100 \mathrm{mg} \cdot \mathrm{L}^{-1}$ kan, out of the surviving cotyledons, 4 weeks after co-cultivation.

"Period of preculture on Induction Medium before Agrobacterium inoculation.

vValues with the same letter within columns are not significantly different (at $p=0.05$ ) according to Tukey and Kramer HSD test (SAS Institute, 1996).

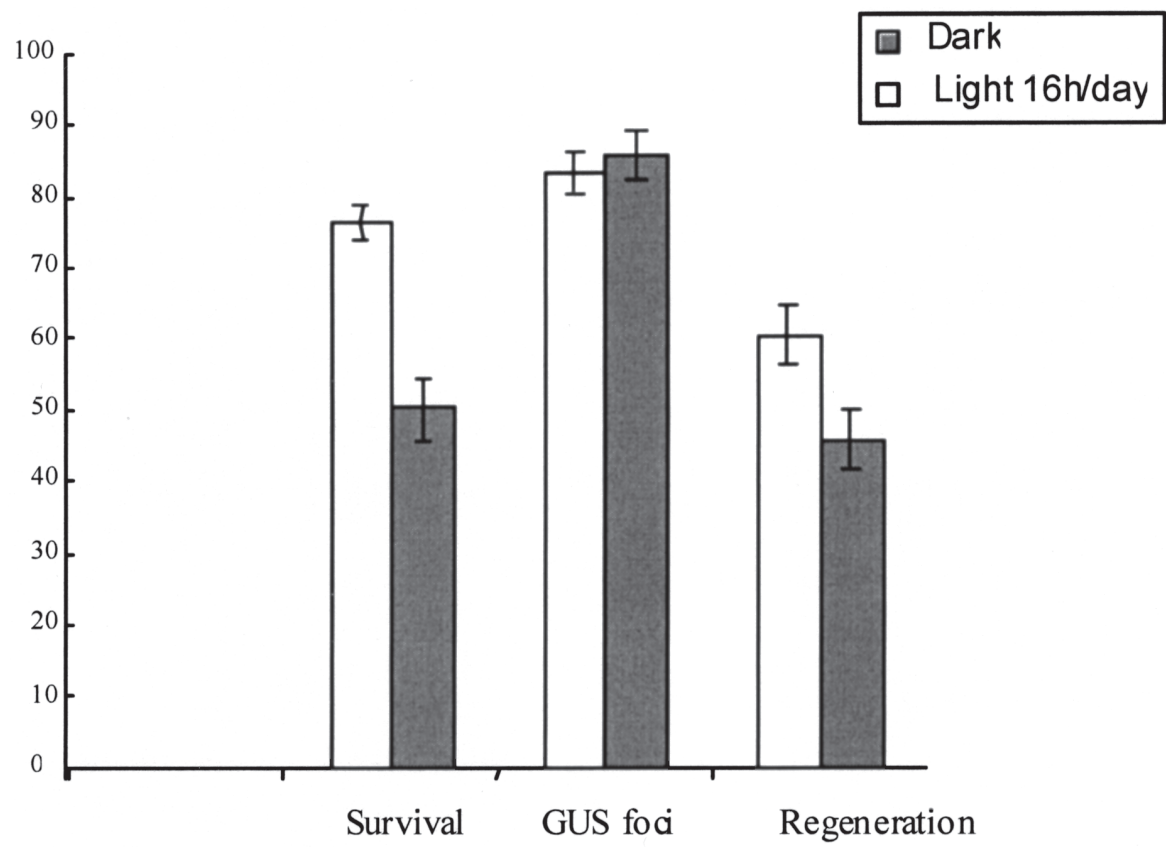

Fig. 2. Effect of Light regime during co-cultivation on the survival rate of explants, transient GUS expression and frequency of regeneration (recorded as in Table 1). Cotyledon explants were co-cultured on MS induction medium for $3 \mathrm{~d}$ and the experiment was replicated three times with 100 cotyledons per replication. 
Table 2. Differences in transient transformation rates using three types of cotyledonary explants. Explants were co-cultured in MS induction medium for $3 \mathrm{~d}$, than subcultured in the same medium with 100 $\mathrm{mg} \cdot \mathrm{L}^{-1} \mathrm{kan}$ and $300 \mathrm{mg} \cdot \mathrm{L}^{-1}$ cefotaxmine.

\begin{tabular}{lccc}
\hline $\begin{array}{l}\text { Explant } \\
\text { type }\end{array}$ & $\begin{array}{c}\text { Surviving } \\
\text { explants }(\%)\end{array}$ & $\begin{array}{c}\text { GUS-positive } \\
\text { explants }(\%)^{\mathrm{z}}\end{array}$ & $\begin{array}{c}\text { GUS-positive } \\
\text { buds }^{\mathrm{y}}(\%)\end{array}$ \\
\hline Type I & $74 \mathrm{c}^{\mathrm{x}}$ & $10 \mathrm{c}$ & $3 \mathrm{c}$ \\
Type II & $85 \mathrm{~b}$ & $30 \mathrm{~b}$ & $10 \mathrm{~b}$ \\
Type III & $90 \mathrm{a}$ & $75 \mathrm{a}$ & $65 \mathrm{a}$ \\
\hline
\end{tabular}

2Percentage of explants showing GUS-activity spots, out of the surviving explants, recorded $7 \mathrm{~d}$ after co-cultivation.

yPercentage of differentiating buds showing GUS activity, out of the surviving explants, recorded 2 weeks after co-cultivation.

${ }^{x}$ Data represent averaged percentages of three replicated experiments, consisting of 100 explants per treatment for each experiment. Different letters indicate a significant difference among treatments according to Duncan multiple range test.

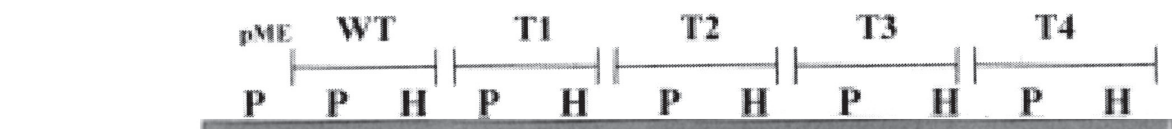

$1.9 \mathrm{~kb}$

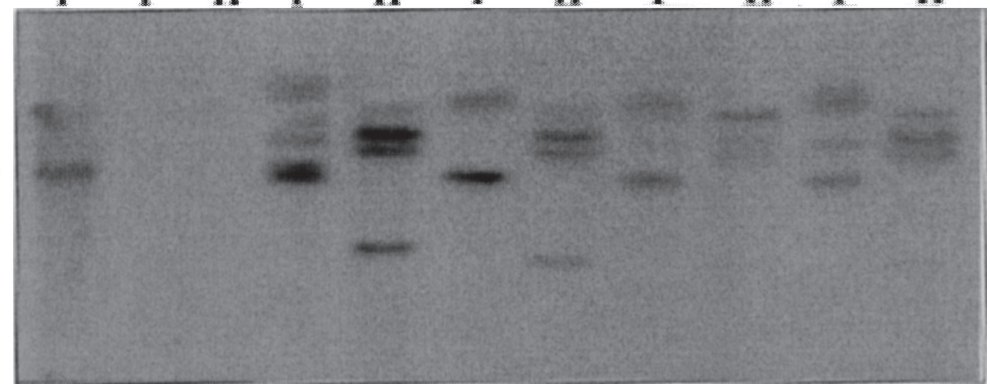

Fig. 3. Southern blot analysis of transgenic plants. Southern blot analysis of genomic DNA of four independent GUS-positive transformed plants (T1-T4) and nontransformed control plants (WT). The DNA (5 $\mu \mathrm{g} / \mathrm{lane})$ was digested with PstI (P) and HindIII (H), and the blot was probed with the $0.6 \mathrm{~kb}$ nptII fragment of pME504. pME $=$ pME504 plasmid DNA digested with Pst I.

We found that the type of explant significantly affected explant survival, as well as the efficiency of both transient and stable transformation (Table 2). Out of the surviving Type III explants, $75 \%$ showed GUS activity, and $65 \%$ subsequently developed kanamycin resistant, GUS-positive adventitious shoots. In contrast, only $30 \%$ of Type II and $10 \%$ of Type I explants showed transient GUS activity. Moreover, only $10 \%$ of Type II, and 3\% of Type I explants developed GUS positive shoots. When these shoots were further selected on increasing kan concentration (see below), shoots originating from Type III explants survived selection and rooted at higher rates than those from Types I and II. We suggest that the wounded region of Type III cotyledons could contain potentially meristematic cells that are susceptible to Agrobacterium, whereas in the other types, cutting occurred in a region with fewer transformation-competent cells. These findings emphasize the importance of explant preparation procedures, i.e., preculturing, pricking and explant excision, that are likely to expose the target cells and render them more competent for transformation.

Regeneration and selection of transgenic shoots. The shoots that developed from the three explant types were regenerated on 100 $\mathrm{mg} \cdot \mathrm{L}^{-1} \mathrm{kan}$. We asked whether optimization of explant preparation and initial culture conditions could result in a higher proportion of stably transformed plants. Previous reports indicated that a high proportion of shoots that differentiated on 75 to $100 \mathrm{mg} \cdot \mathrm{L}^{-1} \mathrm{kan}$ were in fact nontransgenic 'escapes' (Sarmento et al., 1992; Schulze et al.,1995), and we tried to improve the selection regime to minimize the proportion of such shoots.

During the first 3 to 4 weeks on $100 \mathrm{mg} \cdot \mathrm{L}^{-1}$ kan, two kinds of structures were induced on all three explant types, i.e., green shoots and isolated single leaves (Fig. $1 \mathrm{G}$ and $\mathrm{H}$ ). Explants that supported shoot development were moved to elongation medium supplemented with 150 $\mathrm{mg} \cdot \mathrm{L}^{-1}$ kanamycin, while those that did not differentiate were subjected to a second subculture in the induction medium. Applying $150 \mathrm{mg} \cdot \mathrm{L}^{-1}$ kan from the beginning of shoot induction completely suppressed regeneration, therefore a step-wise increase in selection concentration, with $100 \mathrm{mg} \cdot \mathrm{L}^{-1} \mathrm{kan}$ in the initial induction medium was essential. After two weeks on $150 \mathrm{mg} \cdot \mathrm{L}^{-1} \mathrm{kan}$, all shoots originating from explant Types I and II died. In contrast, some of the shoots that differentiated on Type III explants were green and continued to grow, while others bleached and died. Moreover, Type I and Type II cotyledons, when kept under $150 \mathrm{mg} \cdot \mathrm{L}^{-1} \mathrm{kan}$ selection, underwent browning of the meristematic segment and died, whereas in Type III explants, light-green meristematic regions, surrounded by brown tissue, were maintained. Continued culture of these green meristematic regions in the same medium led to proliferation of new buds and shoots (Fig. 1I).

After two additional weeks ( 5 weeks from co-cultivation), actively growing shoots were transferred to fresh selection medium with an increased level of $\mathrm{kan}\left(200 \mathrm{mg} \cdot \mathrm{L}^{-1}\right)$. Some of the shoots remained green and elongated, whereas others bleached and died. Occasionally, longer shoots that were not stably transformed survived for a while on $200 \mathrm{mg} \cdot \mathrm{L}^{-1}$, but were unable to thrive for longer that 3 weeks on such medium. The surviving shoots, on the other hand, multiplied in the presence of $200 \mathrm{mg} \cdot \mathrm{L}^{-1}$ kan, giving rise to several plantlets, collectively designated as one clone (Fig. 1J). The GUS assay was carried out on leaf pieces of such plantlets and GUS-positive ones were recorded as putative transgenic plants. Rooting ability on kan(see below) provided an additional criterion to select for true transformants.

Rooting, hardening and overall efficiency of transgenic plant recovery. Putative transgenic shoots were transferred to Rooting Medium and kanamycin level was decreased to 100 $\mathrm{mg} \cdot \mathrm{L}^{-1}$. After rooting, transgenic cucumber plantlets were transferred to the soil and resumed normal growth in the growth chamber. All the transgenic plants were fully fertile and, following self-pollination, produced seeds in amounts comparable to nontransformed plants. The seeds were obtained 4 to 5 months after co-cultivation. In ten independent experiments, starting from a total of 858 cotyledons, 177 of the explants (21\%) formed shoots after 4 weeks. Ninety-three explants (11\%) produced shoots that were selected as putative transgenic clones on $200 \mathrm{mg} \cdot \mathrm{L}^{-1}$ kanamycin, and about one third of these rooted (3.2\% of original explants). Of the rooted plants, about $50 \%$ were shown to be transgenic by Southern blots (see below). These amounted to 14 confirmed transgenic plants, representing an efficiency of $1.6 \%$ of the initial explants, with one or two plants reproducibly recovered from each of the 10 experiments.

In earlier studies, Tabei et al.(1998) induced shoot regeneration on $25 \mathrm{mg} \cdot \mathrm{L}^{-1} \mathrm{kan}$, followed by transfer to $100 \mathrm{mg} \cdot \mathrm{L}^{-1} \mathrm{kan}$, to eliminate nontransgenic shoots. Sarmento et al. (1992) reported frequent growth of non transformed calli on $75 \mathrm{mg} \cdot \mathrm{L}^{-1}$, and Schulze et al. (1995) reported a large number of escapees among transgenic cucumber plants recovered from suspension culture. Also in melon (Cucumis melo), 30\% to $90 \%$ of the shoots recovered after selection in 75 to $100 \mathrm{mg} \cdot \mathrm{L}^{-1} \mathrm{kan}$ were non transgenic (Fang and Grumet, 1990; Dong et al., 1991). We therefore concluded that stronger selection is vital for efficient cucumber transformation, especially during direct organogenesis from cotyledon explants (see also Gaba et al., 1995). Our unpublished results indicate that the use of phosphinothricin as the selective agent with the bar gene as selective marker is not effective, because it kills transformed explants of most cucumber genotypes. Kanamycin, which under our experimental conditions does not impair the regeneration potential of cotyledons, can achieve effective selection, provided that higher, increasing concentrations are applied. We increased kan concentrations from 100 up to $200 \mathrm{mg} \cdot \mathrm{L}^{-1} \mathrm{kan}$ during shoot induction and elongation, and decreased it back to $100 \mathrm{mg} \cdot \mathrm{L}^{-1}$ for rooting. Such regime, although labor-intensive, seemed to work well and minimize the frequency of escapees to $50 \%$ to $70 \%$ of the total shoots recovered, which is still a high but manageable proportion. When shoots were 
cultured exclusively on $100 \mathrm{mg} \cdot \mathrm{L}^{-1} \mathrm{kan}$, we observed very high proliferation of elongating shoots (data not shown). Assuming a 30\% rooting ratio, we would end up with several hundreds plants that would largely consist of nontransgenic escapees.

Molecular analysis of stably transformed plants. Southern blot analysis was undertaken, to confirm stable integration of the transgene into the genome. Figure 3 displays the results of such analysis for four independent transformants. Genomic DNA $(5 \mu \mathrm{g})$ was digested with PstI and HindIII and hybridized with a $0.6-\mathrm{kb}$ fragment of the nptII gene. PstI cleaves the plasmid twice within the T-DNA, producing an hybridizing 1.9-kb internal T-DNA fragment, as well as a variable junction-fragment that contains both vector and plant-genomic sequences. HindIII cleaves the plasmid only once within the T-DNA, at a distance of 2.3 $\mathrm{kb}$ from the T-DNA right border, resulting in different patterns of hybridization for each transformant. All four plants possessed one or more HindIII fragments $>2.3 \mathrm{~kb}$; in the nontransformed control, no bands were detected. In total, $1.6 \%$ of explants produced 14 transgenic plants that were confirmed by both PCR and Southern blot; the remaining kanamycin-rooted plants were PCR positive but Southern-negative.

To further confirm transgene inheritance, $T_{1}$ seedlings resulting from self-pollination of $\mathrm{T}_{0}$ plants were subjected to PCR analysis using $n p t \mathrm{II}-$ specific primers. The ratio between transformed and nontransformed progeny varied between one family to the other: out of ten families, six segregated for presence versus absence of the transgene in a 3:1 ratio, indicative of a single locus. The other four families deviated from a Mendelian model, with a ratio close to $1: 1$, possibly indicating a chimeric situation in the $\mathrm{T}_{0}$ plants.

\section{Conclusions}

The transformation method reported here provides a modified and improved protocol with respect to previous reports in this crop. Our protocol minimizes the recovery of false positive and chimeric plants by a careful preparation of the explant and selection in increasing kan concentrations. Other important parameters include preincubation of explants prior to inoculation, explant wounding and co-cultivation in the light. At least 14 stably transformed plants could be generated from 858 Type III cotyledon explants. The overall efficiency (stably transformed plants per initial explants) was $1.6 \%$ and the transformed plants were fertile and morphologically normal.

\section{Literature Cited}

An, G., B.D. Watson, and C.C. Chiang. 1986 Transformation of tobacco, tomato, potato and Arabidopsis thaliana using binary vector system. Plant Physiol. 81:301-305.

Boase, M.R., J.M. Bradley, and N.K. Borst. 1998. An improved method for transformation of regal pelargonium (Pelargonium $X$ domesticum Dubonnet) by Agorbacterium tumefaciens. Plant Sci. 139:59-69.

Chee, P.P. 1990a. High frequency of somatic embryogenesis and recovery of fertile cucumber plants. HortScience 25:792-793.

Chee, P.P. 1990b. Transformation of Cucumis sativus L. tissue by Agrobacterium tumefaciens and the regeneration of transformed plants. Plant Cell Rpt. 9:245-248.

Chee, P.P. and J.L. Slightom. 1991. Transfer and expression of cucumber mosaic virus coat protein gene in the genome of Cucumis sativus. J.Amer. Soc. Hort. Sci. $116: 98-102$.

Chilton, M.D., T.C. Currier, S.K. Farrand, A.J. Bendich, M.P. Gordon, and E.W. Nester. 1974. Agrobacterium tumefaciens DNA and PS8 bacteriophage DNAnot detected in crown gall tumors. Proc. Natl. Acad. Sci. USA 71:3672-3676.

Choi, P.S., W.Y. Soh, Y.S. Kim, O.J. Yoo, and J.R. Liu. 1994. Genetic transformation and plant regeneration of watermelon using Agrobacterium tumefaciens. Plant Cell Rpt. 13:344-348.

Dellaporta, S.C., J. Wood, and J.B. Hicks. 1983. A plant DNA minipreparation, version II. Plant Mol. Biol. Rpt. 1:19-21.

Dong, J.Z., M.Z. Yang, S.R. Jia, and N.H. Chua. 1991. Transformation of melon (Cucumis melo L.) and expression from the cauliflower mosaic virus $35 \mathrm{~S}$ promoter in transgenic melon plants. Bio/Technology 9:858-863.

Edelman, M.,A. Perl, M. Flaishman, and A. Blumental, 2000. Transgenic Lemnaceae. Euro. Patent Application 1021552.

Esquinas-Alcazar, J.T., and P.J. Gulick. 1983. Genetic resources of Cucurbitataceae, p 1-101. Intl. Board for Plant Genet. Resour. Secretariat, Rome, Italy.

Fang, G., and Grumet, R. 1990. Agrobacterium tumefaciens-mediated transformation and regeneration of muskmelon plants. Plant Cell Rpt. 9:160-164.

Gaba, V., E. Feldmesser, A. Gal-On, H. Kless, and Y. Antignus. 1995. Genetic transformation of a recalcitrant melon (Cucumis melo L.) variety, $\mathrm{p}$. 188-190. In: L.G. Dunlap et al. (eds.). Cucurbitaceae'94. Gateway Printing.

Ganapathi, A. and R. Perl-Treves. 2000. Agrobacterium-mediated transformation in Cucumis sativus L. via direct organogenesis. In: N. Katzir and H.S. Paris (eds.). Proceedings of Cucurbitaceae-2000. Acta Hort. 510:405-408.

Gomez, K.A., and K.A. Gomez. 1976. Statistical proceures for agricultural research with emphasis of rice. Intl. Rice Res. Inst., Los Bauos.

Jefferson, R.A., T.A. Kavanagh, and M.W. Bevan. 1987. GUS fusion: ß-glucuronidase as a sensitive and versatile gene fusion marker in higher plants. EMBO J. 6:3901-3907.
Kho, Y.O., A.P.M. Den Nijs, and J. Franken. 1980. Intersepecific hybridization in Cucumis L. II. The crossability of species an investigation of in vivo pollen tube growth and seed set. Euphytica 29:66-672.

Kim, S.G., J.R. Chang, H.C. Cha, and K.W. Lee. 1988. Callus growth and plant regeneration in diverse cultivars of cucumber (Cucumis sativus L.). Plant Cell Tiss. Org. Cult. 12:67-74.

Malepszy, S. and N. Orezyk. 1983. In vitro culture of Cucumis sativus. Z Pflanzenphysiol. 111:73-276.

Mohiuddin, A.K.M., K. Harikrishna, M.K.U. Chowdhury, Z.C. Abdullah, and S. Napis. 2000. Influence of acetosyringone on Agrbacteriummediated transformation of cucumber (Cucumis sativus L.). Plant. Tiss. Cult. 10:167-173.

Murashige T. and F. Skoog. 1962. A revised medium for rapid growth and bioassays with tobacco tissue cultures. Physiol. Plant 15:473-498.

Nishibayashi, S., H. Kaneko, and T. Hayakawa. 1996. Transformation of cucumber (Cucumis sativus L.) plants using Agrobacterium tumefaciens and regeneration from hypocotyl explants. Plant Cell Rpt. 15:809-814.

Raharjo, S.H.T, M.O. Hernandez, Y.Y. Zhang, and Z.K. Punja. 1996. Transformation of pickling cucumber with chitinase-encoding genes using Agrobacterium tumefaciens. Plant Cell Rpt. 15:591-596

Raharjo, S.H.T. and Z.K. Punja. 1996. Selection and multiplication of transgenic embryogenic tissues of cucumber using a suspension culture procedure. Cucurbit Gen Cop Rpt. 19:42-46.

Sambrook, J., F.F. Fritsch, and T. Maniatis. 1989. Molecular cloning: A laboratory manual, 2nd edn. Cold Spring Harbor Laboratory Press, Cold Spring Harbor, N.Y.

Sarmento, G.G., K. Alpert, F.A. Tang, and Z.K. Punja. 1992. Factors influencing Agrobactriummediated transformation. Plant Cell Tiss. Org Cult. 31:185-193.

Schulze, J., C. Balko, B. Zellner, T. Koprek, R. Hausch, A. Nerlich, and R.R. Mendal. 1995. Biolistic transformation of cucumber using embryogenic suspension cultures: Long-term expression of reporter gene. Plant Sci. 112:197-206.

Tabei, Y., S. Kitade, Y. Nishizawa, K. Kikuchi, T. Kayano, T. Hibi, and K. Akutsu. 1998. Transgenic cucumber plants harboring a rice chitinase gene exhibit enhanced resistance to gray mold (Botrytis cinerea). Plant Cell Rpt. 17:159-164.

Tabei, Y., T. Nishio, K. Kurihara, and T. Kanuo. 1994. Selection of transformed callus in a liquid medium and regeneration of transgenic plants in cucumber (Cucumis sativus L.). Breed Sci. 44:47-51.

Vengadesan, G., R. Prem Anand, R. Perl-Treves, A. Ganapathi, and S. Amutha. 2005. Transfer and expression of npt II and bar genes in Cucumber (Cucumis sativus L.) In vitro Cell. Dev. Biol.Plant (in press)

Wu, H., C. Sparks, B. Amoah, and H.D. Jones. 2003. Factors influencing successful Agrobacteriummediated genetic transformation of wheat. Plant Cell Rpt. 21:659-668. 